\title{
Algal growth simulation post water regulation in a river-connected lake
}

\author{
H. WANG, Y.Y.ZHOU \& X. WANG \\ Key Laboratory of Integrated Regulation and Resource Development on Shallow Lake of Ministry \\ of Education, College of Environment, Hohai University, Nanjing 210098, China
}

KEYWORD: Algal growth; Model; Numerical simulation; River-connected Lake; Jinshan Lake.

ABSTRACT: We developed a model for algal growth simulation considering flow disturbance, temperature, light intensity and nutrient concentration. Jinshan Lake, a typical river-connect lake at the middle-lower reaches of the Yangtze River, was selected as the research area. According to the simulations on the algal growth processes under the different hydrodynamic conditions of typical water years in Jinshan Lake, we found that: the highest algal concentration values mainly concentrated in July and August of the three typical years. In low water year the days with high algal concentration lasted longer than that in other years for the poor water exchange frequency. Due to the uneven-distributed dynamic conditions, the water surfaces of high algal concentration in the high water year, common water year and low water year were respectively $0.15 \mathrm{~km}^{2}, 0.91 \mathrm{~km}^{2}$ and 1.26 $\mathrm{km}^{2}$.

\section{INTRODUCTION}

There is worldwide concern about algal bloom currently (Tholkapiyan et al. 2014, Lehman 2014, Smida et al. 2014). River-connected lakes with frequent algal bloom is always faced with series of environmental problems such as water quality deterioration, water transparency decrease, ecosystem imbalance, drinking water crisis, human health hazards and so on (McLean \& Sinclair 2012, Lu et al. 2012, Huang 2014). For algal bloom controlling work, previous control before bloom, such as nutrient control, dynamic condition improvement and algal bloom warning, could effectively avoid lots of manpower, material and financial inputs than post-treatment after bloom. In this paper, we placed particular emphasis on algal growth simulation. An integrated hydro-environmental model was established and applied to Jinshan Lake, a typical river-connect lake located in the middle-lower reaches of the Yangtze River, for quantitative algal growth simulation.

\section{METHOdS}

\section{Study area}

Jinshan Lake, as a typical river-connected lake in China, is connected to the Yangtze River by the upstream Leading Channel and the downstream Jiaonan Gate (Fig. 1). Its average surface area is $6.8 \mathrm{~km}^{2}$. Tide in the external Yangtze River results in high and low tides twice a day in Jinshan Lake. Owing to the uneven distributed water volume and suspended sediment in the external Yangtze River, Jinshan Lake is faced with sediment deposition problem in flood season, while in dry seasons, it is faced with water quality deterioration. Under a natural situation, more than $85 \%$ of the water exchange amount between the lake and the Yangtze River is concentrated in the flood seasons. To smooth the contradictions among water volume, water quality and suspended sediment in the lake, the Leading Channel Pumping Station was constructed by the local government in 2010 to regulate the water exchange processes, and have to some extent resolved the environmental problems for the lake. However, the artificial regulation brings a new problem, algal bloom, because it creates a more suitable hydrodynamic condition for algae growth. Therefore, researches on algal growth simulation for bloom warning after artificial water volume regulation is of great importance to protecting the water environment and ecological security for Jinshan Lake. For analysis, Jinshan Lake was divided into five parts according to the underwater elevation distribution, including Area I: Leading Channel, Area II: Mainstream, Area III: North Bottomland, Area IV: South Bottomland, and Area V: Jiaonan Gate (Fig. 2). 


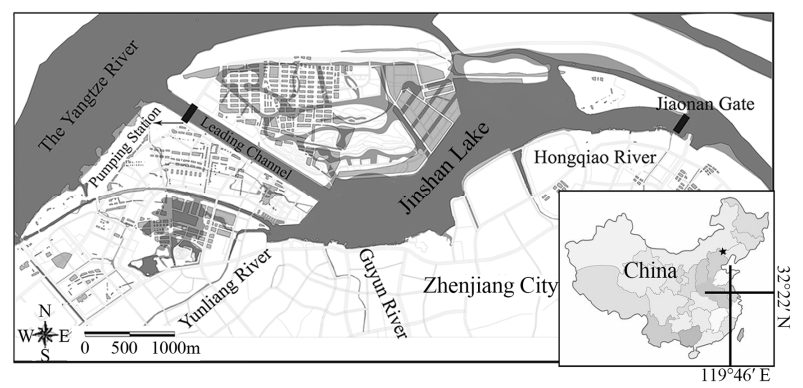

Figure 1. Location of the study area.

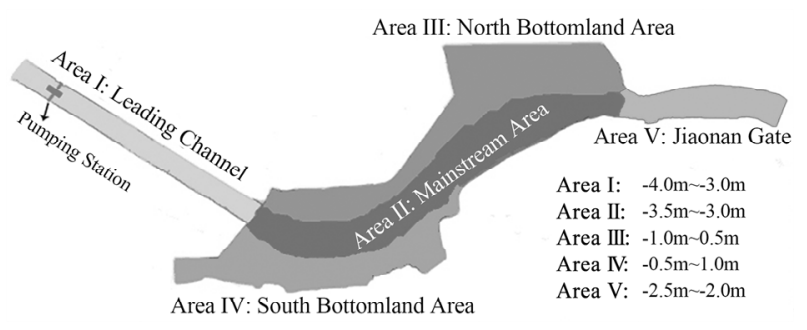

\section{Numerical Model}

Figure 2. Division of Jinshan Lake.

(1) Water current simulation. 1.

The water current process is simulated by two-dimensional shallow water equations as Equation

$$
\left\{\begin{array}{l}
\frac{\partial h}{\partial t}+\frac{\partial(h u)}{\partial x}+\frac{\partial(h v)}{\partial y}=0 \\
\frac{\partial(h u)}{\partial t}+\frac{\partial\left(h u^{2}+g h^{2} / 2\right)}{\partial x}+\frac{\partial(h u v)}{\partial y}=g h\left(s_{0 x}-s_{f x}\right) \\
\frac{\partial(h v)}{\partial t}+\frac{\partial(h u v)}{\partial x}+\frac{\partial\left(h v^{2}+g h^{2} / 2\right)}{\partial y}=g h\left(s_{0 y}-s_{f y}\right)
\end{array}\right.
$$

where $h$ is water depth; $t$ is time; $u$ and $v$ are depth-averaged velocity components in the $x$ and $y$ directions; $g$ is the acceleration of gravity; $s_{0 x}$ and $s_{f x}$ are the bed slope and friction slope in the $x$ direction, and $s_{0 y}$ and $s_{f y}$ are the bed slope and friction slope in the $y$ direction.

(2) Nutrient simulation.

The migration and transformation processes of nutrient are described by the following twodimensional convection-diffusion Equation 2.

$\frac{\partial\left(h C_{i}\right)}{\partial t}+\frac{\partial\left(h u C_{i}\right)}{\partial x}+\frac{\partial\left(h v C_{i}\right)}{\partial y}=\frac{\partial}{\partial x}\left(D_{x}^{i} h \frac{\partial C_{i}}{\partial x}\right)+\frac{\partial}{\partial y}\left(D_{y}^{i} h \frac{\partial C_{i}}{\partial y}\right)-K_{i} h C_{i}+W_{i}$

where $C_{i}$ is the depth-averaged nutrient concentration, $\operatorname{mg} \hat{U}^{-1} ; D_{x}^{i}$ and $D_{y}^{i}$ are the scattering coefficients of nutrient in the $x$ and $y$ directions, $\mathrm{m}^{2} \hat{\mathrm{s}}^{-1} ; K_{i}$ is the degradation coefficient, $\mathrm{d}^{-1} ; W_{i}$ is the source-sink vector of nutrient.

(3) Water temperature simulation.

The water temperature model can be expressed by Equation 3.

$\frac{\partial(h \Delta T)}{\partial t}+\frac{\partial(h u \Delta T)}{\partial x}+\frac{\partial(h v \Delta T)}{\partial y}=\frac{\partial}{\partial x}\left(D_{x}^{t} h \frac{\partial \Delta T}{\partial x}\right)+\frac{\partial}{\partial y}\left(D_{y}^{t} h \frac{\partial \Delta T}{\partial y}\right)-\frac{K_{s}}{\rho C_{p}} \Delta T$

where $\Delta T$ is the temperature difference, ${ }^{\circ} \mathrm{C} ; D_{*}^{i}$ and $D_{v}^{i}$ are the scattering coefficients of water temperature in the $x$ and $y$ directions; $\rho$ and $C_{p}$ are the density and specific heat of water; $K_{s}$ is the heat transfer coefficient, which is calculated by the Gunnerberg empirical formula in the model.

(4) Light intensity simulation.

The attenuation of light intensity in water body is induced by both absorption and scattering (Zhang et al. 2004). Different water bodies are always observed with different physical components, so the light attenuation varies widely and the solar radiations of different wavelengths have various 
attenuation mechanisms in different water layers (Zhang et al. 2003). As many scholars, here, we use the simplified model to recognize the light attenuation coefficient as a constant on the assumption that it does not change with wavelength in the observed depth range. The attenuation process of underwater light intensity is shown in Equation 4 (Kirk 1983).

$$
I_{h}=I_{0} e^{-k h}
$$

where $I_{0}$ is the primary light intensity at the water surface; $h$ is the water depth; $I_{h}$ is the light intensity at the depth of $h ; k$ is the optics attenuation coefficient, which is closely related to the suspended sediment concentration, water transparency, nutrient concentration and other factors (Wang et al. 2008).

(5) Algae concentration simulation.

The algae concentration can be calculated by Equation 5 .

$$
\frac{\partial\left(h C_{c h l-a}\right)}{\partial t}+\frac{\partial\left(h u C_{c h l-a}\right)}{\partial x}+\frac{\partial\left(h v C_{c h l-a}\right)}{\partial y}=\frac{\partial}{\partial x}\left(D_{x} h \frac{\partial C_{c h l-a}}{\partial x}\right)+\frac{\partial}{\partial y}\left(D_{y} h \frac{\partial C_{c h l-a}}{\partial y}\right)+S_{c h l-a}
$$

where $C_{\text {chl-a }}$ is the depth-averaged concentration of $c$ hl-a; $S_{c h l-a}$ is the source-sink vector of $c$ hl-a, of which the expression can be written as in Equation 6.

$$
S_{C h l-a}=(\mu-\text { sed }-d) C_{C h l-a}
$$

where $\mu$, sed and $d$ are respectively the growth rate, deposition rate and loss rate of algae.

(6) Calculation of equations.

The water current, nutrient, temperature, light intensity and algae equations could be combined for calculation. In this paper, the integration and discretization of the equations are conducted in the framework of finite volume method, and the normal numerical flux is calculated by the FVS format. Detailed calculation processes are documented in the references (Zhao et al. 1996, Zhao et al. 2000).

\section{Calculation conditions}

The water exchange between Jinshan Lake and the Yangtze River is regulated by the pumping station at the Leading Channel. Here we selected the water quantity operation schemes for three typical water years, the high water year (1998), common water year (2001) and low water year (2004), to warn algal bloom in the lake. The detailed water exchanging processes in different water years were shown in Figure 3 (Wang et al. 2008).
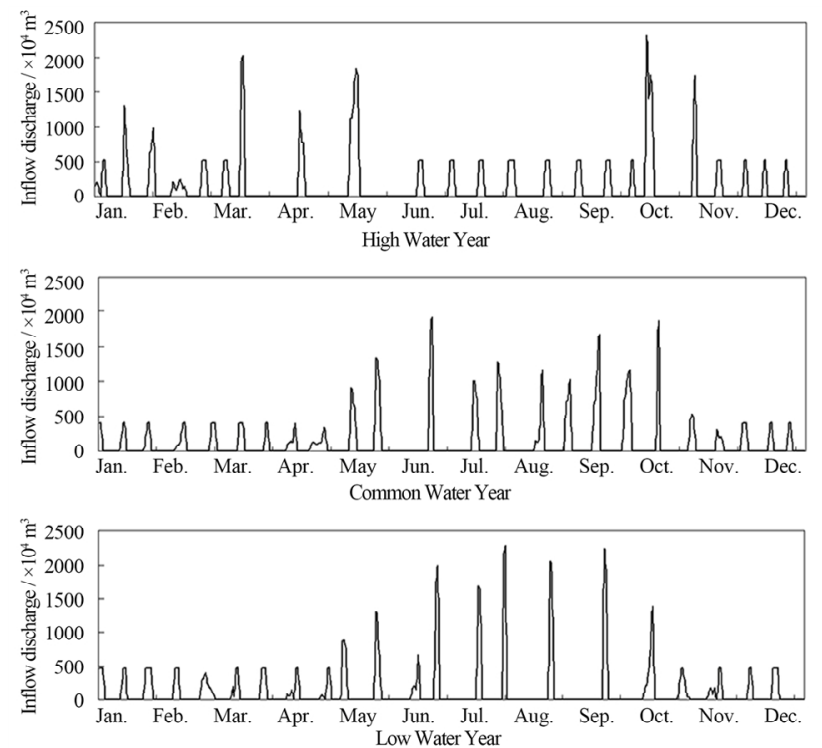

Figure 3. Water regulation schemes in different typical years in Jinshan Lake.

" 1 " represents "Self-introducing". This mode is always used when the water level of the Yangtze River is high enough, and in this situation water exchanges in a natural way. "2" represents "Pumping". This mode is usually selected when the outer water level is too low to precede natural water exchange, and the pumping station will be used in this mode. "0" represents "Keeping static condition". This mode is always needed after water exchange for the sedimentation of suspended sedi- 
ments and the increase of water transparency. The days for self-introducing in high-water year are fewer than that in the other two years because the water level of the Yangtze River in high-water year is higher and the one-time exchanged water quantity is obviously more.

The research area, Jinshan Lake, was divided into 2645 quadrilateral meshes with 2882 nodes by Gambit software, according to the terrain data. The average mesh size is $50 \times 50 \mathrm{~m}$. To guarantee the calculation stability and accuracy the time step $\Delta t$ was taken as $1 \mathrm{~s}$.

\section{RESULTS}

\section{Temporal distribution of algal bloom}

With the given conditions and parameters, algal growth simulation in Jinshan Lake was carried out for different water years based on the established model. The average values of algal concentration in each day of the three typical years were shown in Figure 4. The results showed that:

The highest algal concentration values mainly concentrated in July and August of the three typical years. In the high water year, the algal concentrations in April and May were evidently higher than that in other two years because of the enhanced water exchange and the longer water residence period. In terms of the annual process, the peak value (algal concentration $>10 \mathrm{mg} / \mathrm{m}^{3}$ ) appeared only once in the high water year, while that in the common water year and low water year were both detected for three times. The reason for this was that during the flood seasons of the high water year the inflowing water volume should be controlled for flood security, which increased the water exchange frequency and strengthened the lake water current.

The period with high algal concentration in low water year were respectively increased by $78.8 \%$ and $21.5 \%$ than that in the high water year because the water exchange frequency between Jinshan Lake and the Yangtze River varied remarkably with hydrological conditions. During the low water year the external water level was decreased and the one-time inflowing water volume was needed to be enhanced to meet the water environment need and landscape water level demand. It lengthened the water residence period and provided a more suitable environment for algal growth.

\section{Spatial distribution of algal bloom}

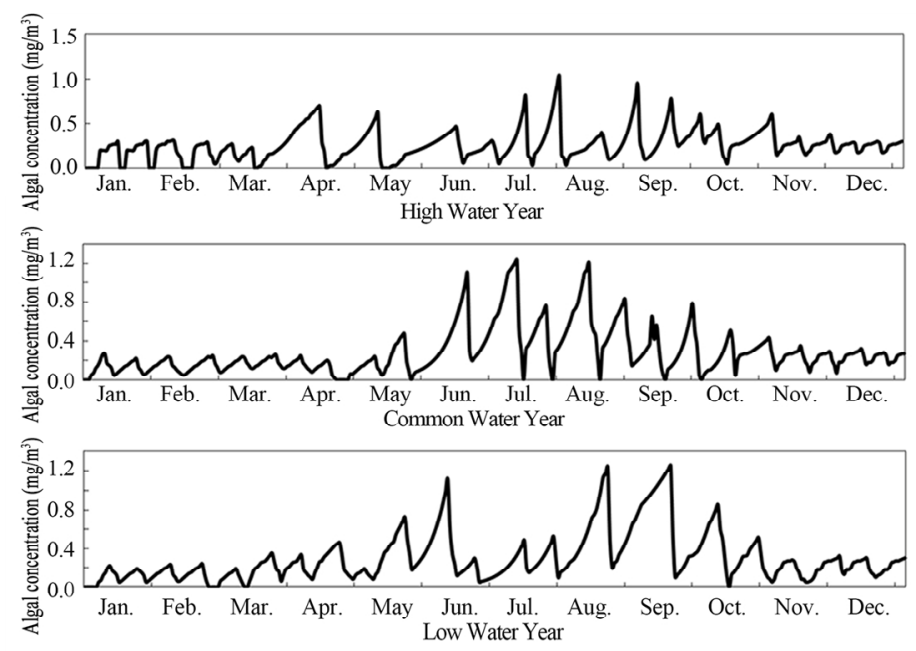

Figure 4. Algal concentration in Jinshan Lake in different years

Based on the calculation results, we picked the spatial distributions of algal concentrations on July 31 in high water year, July 12 in common water year and Sept. 18 in low water year, for study. The three cases separately represented the most serious situation of algal bloom in the three water years (Fig. 5). It was found that:

In different water years the regions with high algal concentration were conformably distributed in the south bottomland, the middle area of mainstream, Jiaonan Gate area, and the entrance area of Leading Channel. Algal bloom could hardly occur in the north bottomland of the lake and the section of the mainstream close to the Leading Channel, because the massive aquatic plants in the former region restrained the algal growth process and the relatively higher suspended sediment concentration in the latter area placed an inhibition on algal growth.

The largest algal concentrations appeared in the south bottomland. This region was located closely to the northern Zhenjiang City and suffered the strong influence of human activities such as 
wasted water input, water current barrier and aquatic plant destroy. The increased nutrient concentration, poor dynamic condition and unbalanced ecosystem created a suitable environment for algae growth. More attention should be paid to this region for algal bloom control.

Due to the different inflowing water volume and water exchange frequency, the total areas suitable for algal growth varied remarkably with level years. The water surfaces of high algal concentration (algal concentration $>10 \mathrm{mg} / \mathrm{m}^{3}$ ) in the high water year, common water year and low water year were respectively $0.15 \mathrm{~km}^{2}, 0.91 \mathrm{~km}^{2}$ and $1.26 \mathrm{~km}^{2}$. As a result of the longer water residence period, the area in low water year was the largest, accounting for about $18.5 \%$ of the total lake area under the most serious status.

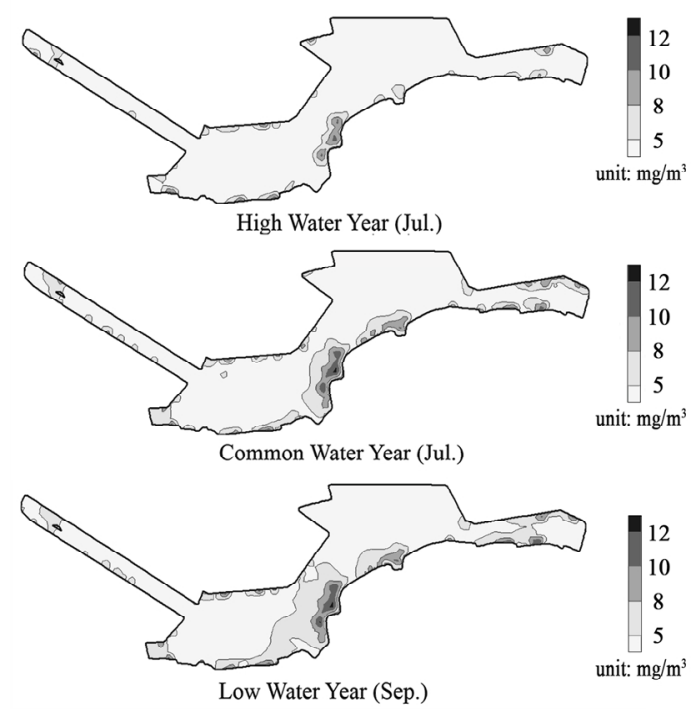

Figure 5. Distribution of algal concentration at the most serious status in the three typical years.

\section{Conclusions}

In this paper, a model for algal growth simulation considering flow disturbance, temperature, light intensity and nutrient concentration was developed. Jinshan Lake, a typical river-connect lake located in middle-lower reaches of the Yangtze River, China, was selected as the research area. The established model was applied to quantitatively simulate the algal growth process in different water years in Jinshan Lake. The results showed that: The highest algal concentration values mainly concentrated in July and August of the three typical years. In the high water year, the algal concentrations in April and May were evidently higher than that in other two years because of the enhanced water exchange and the longer water residence period. The largest algal concentrations appeared in the south bottomland. Therefore, more attention should be paid to the low water year and the south bottomland for algal control. The results of the paper is essential for the ecological environment protection in the research area and is beneficial to the depth study on lake algal bloom warning in the future.

\section{REFERENCES}

[1] Huang, W. 2014. A Comprehensive Control of Cyanobacterial Blooms and Eutrophication. China Rural Water and Hydropower 4: 44-50.

[2] Kirk, J.T.O. 1983. Light and photosynthesis in aquatic ecosystem. Cambridge: Cambridge University Press.

[3] Lehman, J. 2014. Understanding the role of induced mixing for management of nuisance algal blooms in an urbanized reservoir. Lake and Reservoir Management 30: 63-71.

[4] Lu, K., Jin, C. \& Zhu, J. 2012. Controlling Cyanobacteria and Its Effectiveness: An Evaluation in Four Reservoirs for Drinking Water Supply. In B. Han \& Z. Liu (eds), Monographiae Biologicae: 343-362. Netherlands: Springer. 
[5] McLean, T. \& Sinclair, G. 2012. Harmful Algal Blooms. In R. Meyers (eds), Encyclopedia of Sustainability Science and Technology: 4819-4846. New York: Springer.

[6] Smida, D.B., Sahraoui, I., Grami, B., Mabrouk, H.H. \& Hlaili, A.S. 2014. Population dynamics of potentially harmful algal blooms in Bizerte Lagoon, Tunisia. African Journal of Aquatic Science 39: 177-188.

[7] Tholkapiyan, M., Shanmugam, P. \& Suresh, T. 2014. Monitoring of ocean surface algal blooms in coastal and oceanic waters around India. Environ Monit Assess 186: 4129-4137.

[8] Wang, H., Pang, Y., Liu, S.B. \& Ma, X. Research progress on influencing of environmental factors on the growth of submersed macrophytes. 2008. Acta Ecologica Sinica 28: 3958.

[9] Wang, H., Pang, Y., Ding, L., Liu, M., \& Zhuang, H. 2008. Numerical Simulations of the Transparency of Waterfront Bodies. Tsinghua Science and Technology 13: 720-729.

[10]Zhang, Y., Qin, B., Chen, W. \& Yang, D. 2004. Reression Analysis of Beam Attenuation Coefficient under Water in Lake Taihu. Oceanologia Et Limnologia Sinica 35: 209-213.

[11]Zhang, Y., Qin, B., Chen, W., Yang, D. \& Ji, J. Analysis on distribution and variation of beam attenuation coefficient of Taihu Lake's water. 2003. Advances in Water Science 14: 347-353.

[12]Zhao, D., Qi, C., Yu, W., Xu, B. \& Pei, Z. 2000. Volume Method and Riemann Solver for Depth-Averaged Two-Dimensional Flow-Pollutants Coupled Model. Advances in Water Science 11: 368-374.

[13]Zhao, D.H., Shen, H.W., Lai, J.S. \& Tabios, G.Q. Approximate Riemann solvers in FVM for 2D hydraulic shock wave modeling. 1996. J Hydraul Eng-Asce 122: 692-702. 